\title{
Relationship Between Health Care Costs and Very Low Literacy Skills in a Medically Needy and Indigent Medicaid Population
}

\author{
Barry D. Weiss, MD, and Raymond Palmer, PhD
}

Objectives: Previous research established that low literacy is independently associated with poorer health. Our objective was to determine whether low literacy skill also is associated with higher health care charges.

Methods: We studied persons enrolled in Medicaid because of medical need/indigence by testing literacy skills in English or Spanish and measuring annual health care charges. Statistical analyses determined if, after adjusting for sociodemographic variables, literacy was associated with charges.

Results: Mean charges among subjects with very low literacy skills ( $\leq 3 \mathrm{rd}$-grade reading level) were $\$ 10,688$ /year, but only $\$ 2,891$ for those with better literacy skills ( $\geq$ 4th-grade reading level), statistically significant difference $(P=.025)$. This difference persisted after adjustment for potentially confounding sociodemographic variables.

Conclusions: Based on this small study, very limited reading skills seem to be independently associated with higher health care charges among medically needy and medically indigent Medicaid patients. (J Am Board Fam Pract 2004;17:44-7.)

According to the National Adult Literacy Survey, about one quarter of American adults have extremely limited literacy skills. ${ }^{1}$ Research has shown that limited literacy is associated with poor health status, ${ }^{2,3}$ higher hospitalization rates, ${ }^{3}$ limited knowledge about health information, ${ }^{4,5}$ and underuse of preventive health services. ${ }^{6}$ One might hypothesize, therefore, that limited literacy is also associated with higher health care costs.

However, Weiss et $\mathrm{al}^{7}$ found no relationship between literacy and health care costs in a study of Medicaid enrollees in Arizona. Unfortunately, although that study involved over 400 patients, most were enrolled in Medicaid because of pregnancy (which made them eligible for Medicaid benefits). Such young, relatively healthy pregnant women do not have sufficient variation in health care costs to permit detection of a relationship between literacy and costs.

Submitted, revised 8 September 2003.

From the Department of Family and Community Medicine, University of Arizona College of Medicine, Tucson (BDW), and Department of Family and Community Medicine, University of Texas Health Science Center San Antonio, San Antonio (RP). Address correspondence to Barry D. Weiss, MD, Department of Family and Community Medicine, University of Arizona College of Medicine, 1450 North Cherry, Tucson, AZ 85719 (e-mail: bdweiss@ u.arizona.edu).
In this report, we reanalyzed data from the Arizona study after excluding subjects enrolled because of pregnancy. The hypothesis tested was that among the remaining subjects from the study who were enrolled in Medicaid because of medical need or medical indigence (MNMI), those with very low literacy skills would have higher health care charges than did subjects with higher literacy skills.

\section{Methods \\ Subjects}

Subjects were selected using computer-generated random numbers from among enrollees in what was, at the time of the study in 1992, the largest health plan in southern Arizona providing care to enrollees in Arizona's managed-Medicaid plan, the Arizona Health Care Cost Containment System (AHCCCS). Subjects had to be $\geq 18$ years old, speak English or Spanish, and be enrolled continuously in AHCCCS through MNMI eligibility for at least 1 year before study.

\section{Subject Interviews and Literacy Assessments}

All subjects in this study gave informed consent. The written informed-consent process included use of a specially designed low-literacy consent form. Subjects also received an oral explanation of the study and its methods, which were approved by 
the University of Arizona Human Subjects Protection Program.

Each subject underwent a literacy skills test using the Instrument for the Diagnosis of Reading (IDR), ${ }^{8-11}$ which is an English-Spanish instrument; subjects were tested in their preferred language. IDR yields scores from 0 to 8 , corresponding to grade-equivalent reading levels; a score of 8 indicates $\geq 8$ th-grade level.

We categorized subjects with IDR scores $\leq 3$ rdgrade level as having low reading skills and those with scores $\geq 4$ rd-grade level as having higher-level skills. There were 2 reasons for selecting this cutoff level. First, prior studies indicated that health knowledge and health status indicators are particularly poor for subjects with reading skills at or below the 2 nd- or 3 rd-grade level..$^{2-7,9}$ Second, the most widely used health literacy assessment instruments categorizes subjects as being in the lowest level of literacy if reading skills are $\leq 3$ rd-grade level. ${ }^{12,13}$

\section{Measuring Health Care Charges}

We used health plan billing records to tabulate charges for subjects' medical care, which included hospital, emergency department, short-term nursing home, and physician care, plus outpatient and inpatient charges for laboratory, radiographs, pharmacy, and durable medical equipment. These were summed to yield "total charges."

\section{Demographic Variables}

During the interviews, we collected information on each subject's age, self-reported ethnic group, health status, and education level. Health status was measured by asking subjects for a self-assessment of their health (excellent, good, fair, poor).

\section{Data Analysis}

Using SAS software, ${ }^{14}$ we performed $t$ tests to measure differences in health care costs between subjects with low- and high-level reading groups, as defined above. We then performed a multivariable analysis was to determine whether literacy was a predictor of costs after considering age, ethnic group, health status, and education level.

\section{Results \\ Subjects}

There were 74 MNMI subjects, representing 18\% of the original 402 subjects, the remainder of whom
Table 1. Characteristics of Subjects

\begin{tabular}{lcc}
\hline Characteristic & Number & Percentage \\
\hline Sex & & \\
Male & 21 & 71.6 \\
$\quad$ Female & 53 & 28.4 \\
Marital Status & & \\
$\quad$ Single & 28 & 37.8 \\
Divorced & 23 & 31.1 \\
Married & 15 & 20.3 \\
Widow(er) & 8 & 10.8 \\
Ethnicity & & \\
$\quad$ Hispanic & 38 & 52.1 \\
Anglo & 27 & 37.0 \\
Other & 9 & 10.9 \\
Employment Status & & \\
$\quad$ Unemployed & 58 & 78.4 \\
$\quad$ Working & 16 & 21.6 \\
Self-Assessment of Health* & & \\
Excellent & 5 & 6.8 \\
Good & 17 & 23.3 \\
Fair & 33 & 45.2 \\
Poor & 18 & 24.7 \\
Language of Best Reading Skill & & \\
$\quad$ English & 54 & 72.9 \\
Spanish & 20 & 27.0 \\
\hline
\end{tabular}

* There was one missing data point on Self-Assessment of Health.

were enrolled in the Medicaid program through eligibility criteria other than MNMI. The subjects ranged in age from 21 to 77 (mean age of $49.9 \pm$ 13.7) and had completed a mean \pm S.D. of $9.1 \pm$ 4.0 years of education, with a range of 0 to 13 . Table 1 displays other demographic characteristics of subjects.

\section{Reading Levels and Charges for Health Care}

The subjects' mean reading level was at grade 5.4 $( \pm 2.7)$. Eighteen $(24 \%)$ had IDR scores at lowliteracy levels ( $\leq 3 \mathrm{rd}$-grade) and $56(76 \%)$ at higher levels. The 18 low-level readers generated significantly higher annual mean total health care charges than the 56 higher level readers ( $\$ 10,688$ vs $\$ 2,891$; $P=.025)$. This difference was caused principally by differences in inpatient care charges $(\$ 7,038$ vs $\$ 824, P=.020$ ) (Table 2).

The multivariable analysis revealed that reading level was still a significant predictor of costs, even after considering age, ethnic group, and health status $(P=.037)$. In a second analysis that excluded reading level but retained education level, educa- 
Table 2. Annual Health Care Charges for Medically Needy/Medically Indigent Subjects

\begin{tabular}{llc}
\hline Annual Charges & Mean $^{*}$ & Range \\
\hline $\begin{array}{l}\text { Total Charges } \\
\text { Low Literacy } \\
\text { Subjects }(\mathrm{n}=18)\end{array}$ & $\$ 10,688$ & $\$ 0-95,002$ \\
Higher Literacy & & \\
$\quad$ Subjects $(\mathrm{n}=56)$ & $\$ 2890$ & $\$ 0-38,957$ \\
$\begin{array}{c}\text { In-Patient Charges } \\
\text { Low Literacy** } \\
\text { Subjects }(\mathrm{n}=18)\end{array}$ & & \\
Higher Literacy & & \\
Subjects $(\mathrm{n}=56)$ & $\$ 7038$ & $\$ 0-76,884$ \\
\hline
\end{tabular}

* Calculation of mean charges included both subjects who did and whodid not incur charges.

** Low-literacy subjects had reading levels at or below the 3rdgrade level.

*** High-literacy subjects had reading skills at or above the 4th-grade level.

tion level was not a significant predictor of health care charges $(P=.09)$.

\section{Discussion}

The key finding of this study is that persons with low-literacy skills generate higher charges for health care than do persons with better reading skills. The difference was large, statistically significant, and clinical meaningful. It supports results of other research, which has found that persons with limited literacy skills have poorer health status, are more apt to be hospitalized, and make more visits to emergency rooms than their more literate counterparts. ${ }^{15-17}$ Indeed, one analysis has suggested that excess hospitalizations and other ramifications of limited literacy cost the US health care system between $\$ 50$ to 73 billion per year. ${ }^{18}$

The key finding of the study is supported by the multivariable analysis, in which literacy was a predictor of health care costs independent of the other sociodemographic variables that we measured. Furthermore, all subjects in this study were Medicaid enrollees and, as such, they were mostly unemployed or employed at low-paying jobs, indicating that they all had similar socioeconomic status.

Nonetheless, for several reasons, the results of this study are preliminary. First, they are based on secondary analyses of a larger data set from a previous study. Second, the findings are based on data from a small numbers of subjects, raising the pos- sibility that the higher costs found in the lowliteracy group could have been attributable to the chance occurrence of high-cost illness in a few subjects. Third, there may have been other factors, not measured in this study, that contributed to health costs. Thus, additional investigation is needed to confirm the results of this study, and to further explore the basis of the relationship between literacy and health care costs.

We acknowledge those who participated in the conception and analysis of the earlier study on which this report is based. These individuals include Jay S. Blanchard, PhD; Daniel L. McGee, PhD; Gregory Hart, MA; Barbara Warren, MD, MPH; Michael Burgoon, PhD; and Kenneth Smith, EdD. We also appreciate Denise Stallcup's assistance in editing the manuscript.

\section{References}

1. Kirsch I, Jungeblut A, Jenkins L, Kolstad A. Adult literacy in america: a first look at the results of the National Adult Literacy Survey. Washington DC: National Center for Education Statistics, US Department of Education; 1993.

2. Weiss BD, Hart G, McGee DL, D'Estelle S. Health status of illiterate adults: relation between literacy and health status among persons with low literacy skills. J Am Board Fam Pract 1992;5:257-64.

3. Baker DW, Parker RM, Williams MV, Clark WS, Nurss J. The relationship of patient reading ability to self-reported health and use of health services. Am J Public Health 1997;87:1027-30.

4. Williams MV, Baker DW, Parker RM, Nurss JR. Relationship of functional health literacy to patients' knowledge of their chronic disease: a study of patients with hypertension or diabetes. Arch Intern Med 1998:166-72.

5. Williams MV, Baker DW, Honig EG, Lee TM, Nowlan A. Inadequate literacy is a barrier to asthma knowledge and self-care. Chest 1998;114:1008-15.

6. Rimer B, Trock B, Engstrom P. Why do some women get regular mammograms? Am J Prev Med. 1991;7:69-73.

7. Weiss BD, Blanchard JS, McGee DL, et al. Illiteracy among Medicaid recipients and its relationship to health care costs. J Health Care Poor Underserved. 1994;5:99-111.

8. Blanchard JS, Garcia HS, Carter RM. Instrumento para diagnosticar lecturas (Español-English): instrument for the diagnosis of reading. Dubuque (IA): Kendall-Hunt Publishing Co.; 1989.

9. Silvaroli N. Classroom reading inventory, 3rd ed. New York: William C. Brown; 1986.

10. John J. Basic reading inventory, 5th ed. Dubuque (IA): Kendall-Hunt; 1985. 
11. Blanchard J. Microcomputer based reading assessment. Comp Schools 1989;6:111-21.

12. Davis TC, Long S, Jackson R, et al. Rapid estimate of adult literacy in medicine: a shortened screening instrument. Fam Med 1993;25:391-5.

13. Murphy PW, Davis TC, Decker BC, Jackson RH. Rapid estimate of adult literacy in medicine: using a novel reading recognition tests. Journal of Reading 1993;37:124-30.

14. SAS/STAT user's guide, Version 6, 4th ed. Vol. 1. Cary (NC): SAS Institute Inc.; 1989.

15. Baker DW, Gazmararian JA, Williams MV, et al. Functional health literacy and the risk of hospital admission among Medicare managed care enrollees. Am J Public Health. 2002;92:1278-83.

16. Baker DW, Parker RM, Williams MV, Clark WS, Nurss J. The relationship of patient reading ability to self-reported health and use of health services. Am J Public Health 1997;87:1027-30.

17. Schillinger D, Grumbach K, Piette J, et al. Association of health literacy with diabetes outcomes. JAMA 2002;288:475-82.

18. Friedland RB. Understanding health literacy: new estimates of the costs of inadequate health literacy. Washington DC: National Academy on an Aging Society; 1998. 